Rev. Int. Contam. Ambie. 34 (4) 651-665, 2018

DOI: 10.20937/RICA.2018.34.04.08

\title{
ANÁLISIS DE TENDENCIAS DE VARIABLES INDICADORAS DE CALIDAD DE AGUA PARA EL RIACHUELO (CUENCA MATANZA-RIACHUELO, ARGENTINA)
}

\author{
María Victoria CASARES* y Laura Isabel DE CABO
}

Museo Argentino de Ciencias Naturales Bernardino Rivadavia-Consejo Nacional de Investigaciones Científicas y Técnicas (CONICET), Av. Ángel Gallardo 470, C1405DJR Buenos Aires, Argentina

*Autor para correspondencia; mvc251@hotmail.com

(Recibido diciembre 2016; aceptado marzo 2018)

Palabras clave: río urbano, contaminación, efluentes, escorrentía pluvial

\section{RESUMEN}

El río Matanza-Riachuelo constituye un ejemplo claro y extremo del "síndrome del río urbano" y un caso emblemático de contaminación en Argentina. A partir de los datos generados en el monitoreo de la calidad de agua superficial del Riachuelo (tramo inferior del río Matanza) que realiza la Agencia de Protección Ambiental del Gobierno de la Ciudad de Buenos Aires, se evaluó la evolución de la calidad del agua (periodo 2008-2016). Para ello, se aplicó la prueba estadística de Mann-Kendall a la serie de datos para cinco variables fisicoquímicas, una microbiológica y la precipitación acumulada mensual para el área. Los resultados reflejaron condiciones más favorables en cuanto a contenido y demanda biológica de oxígeno, nitrógeno amoniacal total y ion cloruro aguas arriba de la desembocadura. La abundancia de bacterias Escherichia coli no mostró una tendencia apreciable. Asimismo, la fracción de materia orgánica no biodegradable se habría incrementado en todo el tramo al igual que la precipitación acumulada mensual para el periodo estudiado. El incremento de la escorrentía pluvial habría determinado las tendencias observadas en el intervalo de tiempo considerado. Aun así, el ecosistema permaneció en un estado altamente degradado con el $50 \%$ de los valores registrados de oxígeno disuelto por debajo de $2 \mathrm{mg} / \mathrm{L}$ y el $50 \%$ de los valores de demanda biológica y demanda química de oxígeno por encima de 15 y $50 \mathrm{mg}$ $\mathrm{O}_{2} / \mathrm{L}$, respectivamente. Los números de $E$. coli, por su parte, resultaron similares a los de un efluente cloacal crudo.

Key words: urban river, pollution, sewage, stormwater runoff

\begin{abstract}
The Matanza-Riachuelo river is a clear and extreme example of the "urban river syndrome" and an emblematic case of environmental pollution in Argentina. Analysis of water quality data trends for the Riachuelo (in the Matanza-Riachuelo river lower basin) was performed by using water quality monitoring data generated by the Environmental Protection Agency of the Buenos Aires City Government. Data was collected in three monitoring points along the river from 2008 to 2016. The Mann-Kendall non-parametric statistical test was applied to the time series available for six parameters, five physicochemical and one microbiological, and the monthly rainfall data for the Buenos Aires City area. Trend analysis showed an improvement in the quality of Riachuelo's surface water, reflected by increasing levels in dissolved oxygen (upstream the river mouth) and
\end{abstract}


decreasing levels in biological oxygen demand, total ammonia nitrogen and chloride. Non-biodegradable organic matter, in contrast, showed an increasing trend. Monthly rainfall also experienced an increment while Escherichia coli numbers did not show a defined pattern. Increasing stormwater runoff may have determined the trends observed in the time period considered. Nonetheless, the quality of Riachuelo's water remained severely degraded with $50 \%$ of the dissolved oxygen, and biological and chemical oxygen demands values below $2 \mathrm{mg} / \mathrm{L}$ and above 15 and $50 \mathrm{mg} \mathrm{O}_{2} / \mathrm{L}$, respectively. $E$. coli numbers were similar to those recorded in raw sewage.

\section{INTRODUCCIÓN}

Las poblaciones humanas tradicionalmente se han asentado próximas a cuerpos de agua. Un fiel reflejo de ello son la mayoría de las ciudades capitales en el mundo, asentadas en las márgenes de lagos, ríos y estuarios importantes, con fines no sólo estratégicos para la defensa y transporte, sino de provisión de agua para consumo y eliminación de desechos. El crecimiento poblacional de los primeros asentamientos y su posterior urbanización, llegando a las megaciudades de la actualidad, han impuesto altas presiones sobre estos ecosistemas acuáticos, lo que ha resultado en ambientes altamente degradados. Múltiples factores afectan de manera simultánea estos cuerpos de agua y, si bien la descarga de aguas residuales municipales e industriales constituye una fuente de contaminación muy importante y constante (Varol y Sen 2009), en muchos casos resulta difícil identificar por completo todas las causas que llevan al deterioro biológico de estos ecosistemas.

Al conjunto de impactos típicos que presentan los ecosistemas acuáticos urbanos Walsh et al. (2005) lo han denominado "síndrome del río urbano". Entre estos impactos se encuentran: hidrogramas con picos pronunciados, elevada concentración de nutrientes y contaminantes, morfología y estabilidad del cauce alteradas y riqueza biótica reducida con dominancia de especies tolerantes. Los ríos urbanos caracterizados por caudales base muy bajos suelen ser ríos dominados por efluentes. Es decir, sus aguas superficiales consisten primariamente en las descargas de efluentes no tratados, tratados y de la escorrentía pluvial; por lo tanto, presentan características fisicoquímicas propias y un régimen hidrológico diferente a otros cursos de referencia (Brooks et al. 2006).

En la Argentina, el río Matanza-Riachuelo es un claro ejemplo de un caso extremo de síndrome del río urbano. Este curso, principal motivo de la actual ubicación de la ciudad de Buenos Aires, ha sido testigo y víctima del crecimiento poblacional e industrialización de la urbe argentina más importante.
Con una pendiente muy escasa y bajos caudales, el Matanza-Riachuelo presenta una capacidad de autodepuración muy limitada (AGN 2006). A ello debe sumarse el efecto de las mareas del río de la Plata y los fenómenos de sudestada que impiden el libre desagüe de las aguas del Riachuelo. Históricamente, en sus márgenes se han desarrollado actividades que han contaminado sus aguas de manera indiscriminada. Desde la conquista, en la cuenca baja se instalaron saladeros, curtiembres, lavaderos de lana y mataderos; posteriormente, se asentó ahí una amplia gama de industrias. El Matanza-Riachuelo recibe descargas industriales directas, efluentes líquidos cloacales de descarga difusa y puntual - con y sin tratamiento - y los desagües pluviales de la ciudad con conexiones cloacales e industriales clandestinas. Asimismo, en ciertas áreas se utiliza el curso como vertedero de residuos sólidos urbanos, y en la cuenca también hay presencia de basurales a cielo abierto. Además, el río Matanza-Riachuelo sufrió, a lo largo del tiempo, importantes modificaciones en su cauce (rectificación y canalización). El resultado es un ecosistema altamente impactado, con una riqueza específica reducida a las especies más tolerantes.

De acuerdo con un estudio realizado por Aguas Argentinas entre 1997 y 2001 (Fundación Ciudad 2002), las condiciones ambientales indicaron contaminación extrema del curso principal (valores de oxígeno disuelto inferiores a $3 \mathrm{mg} / \mathrm{L}$ y valores de demanda biológica de oxígeno, expresada como $\mathrm{DBO}_{5}$, entre 15 y $20 \mathrm{mg} \mathrm{O}_{2} / \mathrm{L}$ ) para la cuenca media y baja. Asimismo, un estudio realizado por la organización no gubernamental Greenpeace indicó que las concentraciones de varios metales en el sedimento superaban de modo amplio los niveles guía para sedimentos establecidos por la normativa holandesa (marco de referencia utilizado dada la ausencia de niveles guía nacionales para sedimentos) (Cuadro I). El estudio también detectó la presencia de compuestos orgánicos de uso industrial (fenólicos, organohalogenados, hidrocarburos aromáticos policíclicos y alquilbencenos, entre otros). 
CUADRO I. CONCENTRACIÓN DE METALES (mg/kg PESO SECO) EN SEDIMENTOS DEL RÍO MATANZA-RIACHUELO EN SU CUENCA BAJA

\begin{tabular}{lccccc}
\hline & $\begin{array}{c}\text { Riachuelo } \\
\text { Puente La Noria }\end{array}$ & $\begin{array}{c}\text { Riachuelo } \\
\text { Puente Uriburu }\end{array}$ & $\begin{array}{c}\text { Riachuelo } \\
\text { Puente Avellaneda }\end{array}$ & $\begin{array}{c}\text { Normativa } \\
\text { holandesa* }\end{array}$ & $\begin{array}{c}\text { Normativa } \\
\text { argentina** }\end{array}$ \\
\hline $\mathrm{Cd}$ & 1 & 5 & 2 & 0.8 & 3 \\
$\mathrm{Cr}$ & 170 & 1648 & 1099 & 100 & 750 \\
$\mathrm{Cu}$ & 250 & 325 & 229 & 36 & 150 \\
$\mathrm{~Pb}$ & 201 & 407 & 211 & 85 & 375 \\
$\mathrm{Zn}$ & 938 & 936 & 927 & 140 & 600 \\
$\mathrm{Hg}$ & 1.76 & 2.3 & 0.89 & 0.3 & 0.8 \\
$\mathrm{Ni}$ & 41 & 46 & 40 & 35 & 150 \\
\hline
\end{tabular}

*Normas holandesas para suelos y sedimentos (Bridgen et al. 2000)

**Niveles guía de calidad de suelos. Uso agrícola (MJyDH 1993)

La Autoridad de Cuenca Matanza-Riachuelo (ACUMAR) fue creada en 2006 a partir de la judicialización del conflicto ambiental del Riachuelo como un ente de derecho público interjurisdiccional que constituye la máxima autoridad en materia ambiental para la cuenca. En 2009, ACUMAR presentó un Plan Integral de Saneamiento Ambiental (PISA) donde se propuso como meta u objetivo ambiental para la cuenca en el mediano a largo plazo un "uso apto para actividades recreativas pasivas" (uso IV) que tiene asociados criterios de calidad de agua para 11 parámetros fisicoquímicos. El uso IV implica actividades recreativas que apuntan sólo al disfrute estético (apreciación del paisaje, circuitos pedestres, sendas para caminar, ciclismo) (ACUMAR 2009).

El gobierno de la Ciudad Autónoma de Buenos Aires (GCABA) a través de la Agencia de Protección Ambiental (APRA-GCABA) lleva a cabo, al igual que la ACUMAR, un programa de monitoreo de la calidad del agua superficial mensual del Riachuelo y otros cursos en el territorio de la ciudad.

El objetivo del presente estudio es evaluar la evolución de la calidad del agua del Matanza-Riachuelo en su cuenca baja (Riachuelo) a través de un análisis estadístico de tendencias de variables indicadoras de contaminación orgánica, de una variable conservativa como el ion cloruro y de la precipitación acumulada mensual para el área.

\section{MATERIALES Y MÉTODOS}

\section{Área de estudio}

La cuenca del río Matanza-Riachuelo (Fig. 1) se encuentra ubicada en la región centro-este de la llanura pampeana, más precisamente en la Pampa Ondulada, y comprende un territorio de aproximadamente $2200 \mathrm{~km}^{2}$. Con una longitud total de $64 \mathrm{~km}$, el río
Matanza-Riachuelo nace por el aporte de los arroyos Rodríguez o de los Pozos, Cañuelas y Morales. El curso principal drena en dirección SO-NE. El último tramo es denominado Riachuelo. De acuerdo con la información provista por Falczuk (2010), el caudal medio anual estimado para el río Matanza en el tramo rectificado es de $7.02 \mathrm{~m}^{3} / \mathrm{s}$, con un caudal máximo de $1325 \mathrm{~m}^{3} / \mathrm{s}$. El ancho del cauce es de 60 metros en el punto de entrada a territorio jurisdiccional de la CABA y 97 metros en su desembocadura en el río de la Plata (ACUMAR 2016a) (Fig. 1). La profundidad media en el centro del cauce en el punto de entrada a territorio de la CABA y debajo del Puente Transbordador Nicolás Avellaneda (Fig. 1), cercano a la desembocadura, es de $1.42 \pm 0.4$ y $2.97 \pm 0.60 \mathrm{~m}$, respectivamente (ACUMAR 2016b). El territorio de la cuenca está integrado por la CABA y 14 municipios de la provincia homónima (Malpartida 2003). La cuenca se emplaza en la zona más urbanizada e industrializada del país, con cerca de tres millones de habitantes asociados a ella. El $55 \%$ de la población vinculada a la cuenca no tiene acceso a la red de saneamiento. Además, el río Matanza recibe los efluentes de tres plantas depuradoras de líquidos cloacales de la empresa Aguas y Saneamientos Argentinos (AySA), donde se realiza un tratamiento secundario (lecho percolador/barros activados). AySA presta servicio a más de un millón de habitantes y recibe descargas diarias de 250 camiones con líquidos provenientes de descargas mixtas. Entre las principales actividades industriales que constituyen agentes contaminantes se encuentran curtiembres, frigoríficos y carnes y derivados; industrias químicas, petroquímicas, de alimentos y bebidas, y galvanoplastias.

\section{Análisis estadístico}

Con una periodicidad variable, la APRA-GCABA realiza muestreos de agua superficial en el centro del cauce del Riachuelo en tres puntos: Puente 


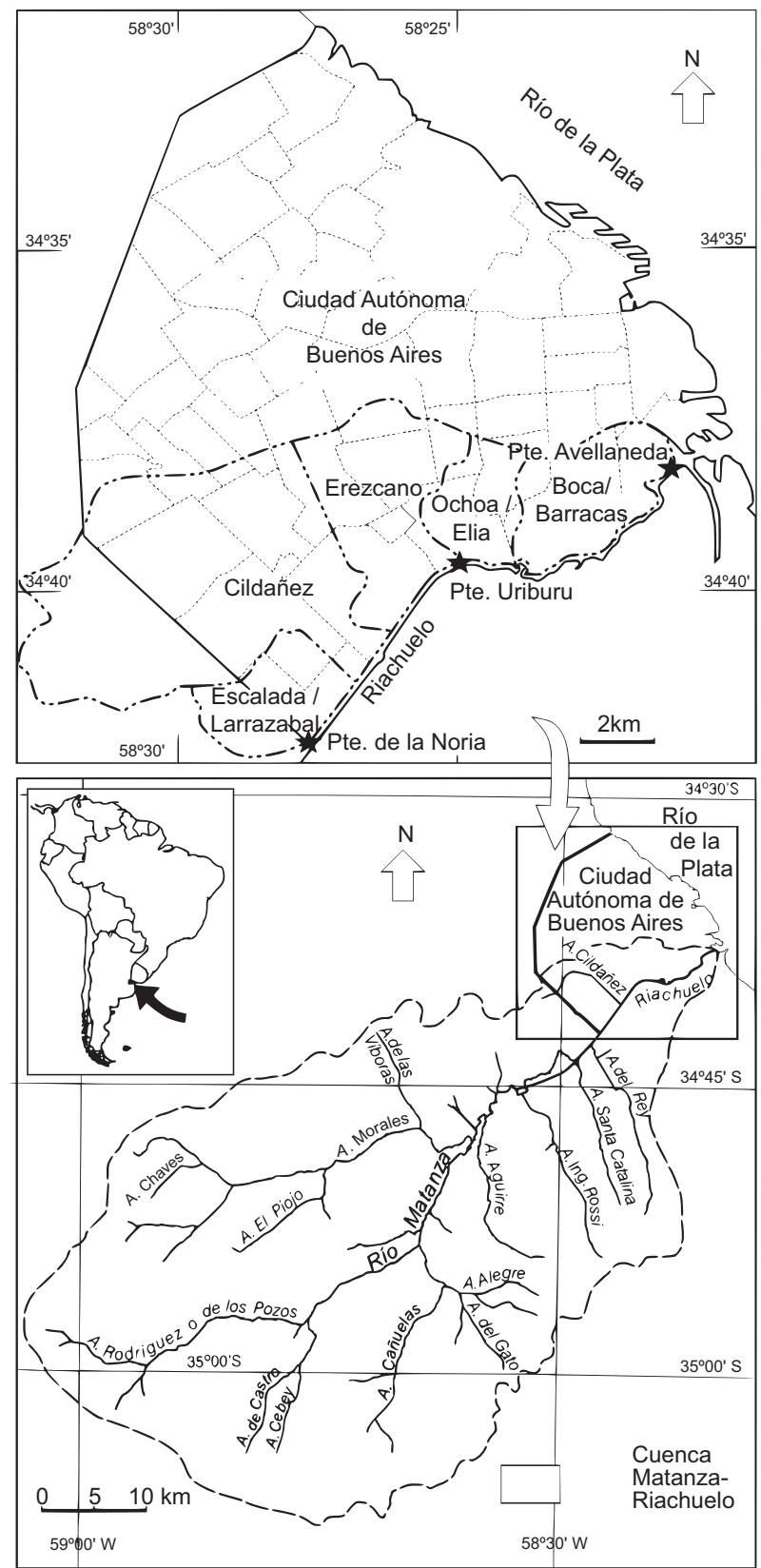

Fig. 1. Mapa de la cuenca Matanza-Riachuelo y detalle del curso en su cuenca baja (Riachuelo) con estaciones de monitoreo (Puente la Noria, Puente Uriburu y Puente Avellaneda) y subcuencas hidrográficas que drenan las aguas de escorrentía pluvial de la Ciudad Autónoma de Buenos Aires

La Noria ( $34^{\circ} 42^{\prime} 18.41^{\prime}$ S, $58^{\circ} 27^{\prime} 39.82^{\prime}$ W), Puente Uriburu ( $34^{\circ} 39^{\prime} 34.60^{\prime \prime} \mathrm{S}, 58^{\circ} 25^{\prime} 0.70^{\prime \prime}$ W) y justo debajo del Puente Transbordador Nicolás Avellaneda (34 38' 19.26" S, 58 21'23.11”W) (Fig. 1). En dicho monitoreo se determinan 27 parámetros fisicoquímicos y ocho variables microbiológicas de calidad del agua. Para el presente estudio, se seleccionaron los siguientes parámetros indicadores de contaminación orgánica: oxígeno disuelto (OD), demanda biológica de oxígeno $\left(\mathrm{DBO}_{5}\right)$, demanda química de oxígeno (DQO), nitrógeno amoniacal total $\left(\mathrm{N}-\mathrm{NH}_{3}\right.$, de aquí en adelante NAT) y abundancia de bacterias Escherichia coli expresada en unidades formadoras de colonia por 100 mililitros (UFC/100 $\mathrm{mL}$ ). Asimismo, se incluyó en el análisis un parámetro conservativo como el ion cloruro $\left(\mathrm{Cl}^{-}\right)$. A excepción del oxígeno disuelto medido in situ con oxímetro (Orion 3 Star), el resto de los parámetros se determinó en muestras de agua de acuerdo con métodos estandarizados (APHA/AWWA/WPCF 1992). Los datos utilizados para el presente estudio fueron sido provistos por la APRA a través de la Gerencia Operativa Riachuelo y Borde Costero, y constituyen toda la serie temporal disponible de 2008 a 2016. Los datos de precipitación acumulada mensual para la CABA en dicho periodo se obtuvieron del gobierno de la Ciudad de Buenos Aires (Buenos Aires Ciudad 2016a).

La presencia de tendencias estadísticamente significativas en la serie de tiempo considerada para los parámetros de calidad de agua seleccionados y la precipitación acumulada mensual se evaluó a partir de la aplicación de la prueba no paramétrica de Mann-Kendall (Mann 1945, Kendall 1975). Esta prueba tiene dos ventajas: primero, no requiere una distribución normal de los datos y, segundo, tiene baja sensibilidad a series de tiempo poco homogéneas (Tabari et al. 2011). De acuerdo con esta prueba, la hipótesis nula $(\mathrm{H} 0)$ asume la no existencia de una tendencia (los datos son independientes y se encuentran ordenados al azar) y esto es contrastado con la hipótesis alternativa (H1), que asume la existencia de una tendencia en los datos (Onoz y Bayazit 2003).

Básicamente, los valores son evaluados como series de tiempo ordenadas. Cada valor es comparado con todos los valores subsecuentes. Si un valor de un periodo de tiempo posterior es mayor al valor de un periodo de tiempo anterior, el estadístico $S$ se incrementa en 1. Por otro lado, si se produce lo contrario, $S$ disminuye en 1 . El resultado neto de todos los incrementos y reducciones resulta en el valor final de $S$. Si n $<10$, el valor de $S$ se compara directamente con la distribución teórica de $S$ derivada por Mann y Kendall. La prueba de dos colas es aplicada. A cierto nivel de probabilidad, la hipótesis nula es rechazada si el valor absoluto de $S$ iguala o excede un valor especifico $S \alpha / 2$, donde $S \alpha / 2$ es el $S$ mas pequeño que tiene una probabilidad $\alpha / 2$ de de aparecer en caso de 
no haber tendencia. Un valor positivo de $S$ indica una tendencia en incremento mientras que un valor negativo indica lo contrario (Drapela y Drapelova 2011). Para $\mathrm{n}>10$, el estadístico $S$ se distribuye normalmente.

Otro estadístico que se obtiene al aplicar la prueba de Mann-Kendall es el tau de Kendall, que constituye un coeficiente de correlación por rangos y por lo tanto mide la fuerza de la relación entre las dos variables. En forma similar a otras medidas de correlación, el tau de Kendall toma valores entre $1 \mathrm{y}-1$, con una correlación positiva indica que los rangos de las dos variables se incrementan en conjunto mientras que una correlación negativa indica que cuando los rangos de una variable aumentan, los rangos de la otra variable disminuyen (Crichton 2001).

Antes de la aplicación de la prueba de Mann-Kendall se removieron los valores atípicos que podrían generar tendencias aparentes. La autocorrelación o correlación serial en los datos se consideró mediante la aplicación de la prueba de Hamed y Rao (1998). En este caso, la hipótesis nula fue probada con un nivel de confianza del $90 \%(\mathrm{p}<0.10)$.

El análisis estadístico de los datos fue realizado utilizando el programa XLSTAT v. 2013.5.09 de Addinsoft. En todos los casos la hipótesis nula fue probada con un nivel de confianza del $95 \%$ $(\mathrm{p}<0.05)$.

\section{RESULTADOS}

\section{Oxígeno disuelto}

Los valores medio y de la mediana del oxígeno disuelto (cuadro II) se encontraron en torno a $2 \mathrm{mg} / \mathrm{L}$. En Puente Uriburu ambos valores resultaron levemente menores de $2 \mathrm{mg} / \mathrm{L}$, ya que cerca del $80 \%$ de las mediciones fueron inferiores a este nivel, que es el criterio de mínimo admisible previsto en el uso IV "actividades recreativas pasivas" para OD. En Puente la Noria y Puente Avellaneda ambos estadísticos alcanzaron los $2 \mathrm{mg} / \mathrm{L}$. El rango de variación fue pequeño en todos los casos y el valor máximo $(7.21 \mathrm{mg} / \mathrm{L})$ se registró en Puente Avellaneda.

Las tendencias crecientes en los valores de oxígeno disuelto (Fig. 2) fueron estadísticamente significativas en Puente la Noria y Puente Uriburu. La correlación entre este parámetro y la variable tiempo, reflejada en el valor tau de Kendall, fue visiblemente mayor en ambas estaciones respecto a Puente Avellaneda, que mostró una tendencia de incremento pero estadísticamente no significativa.

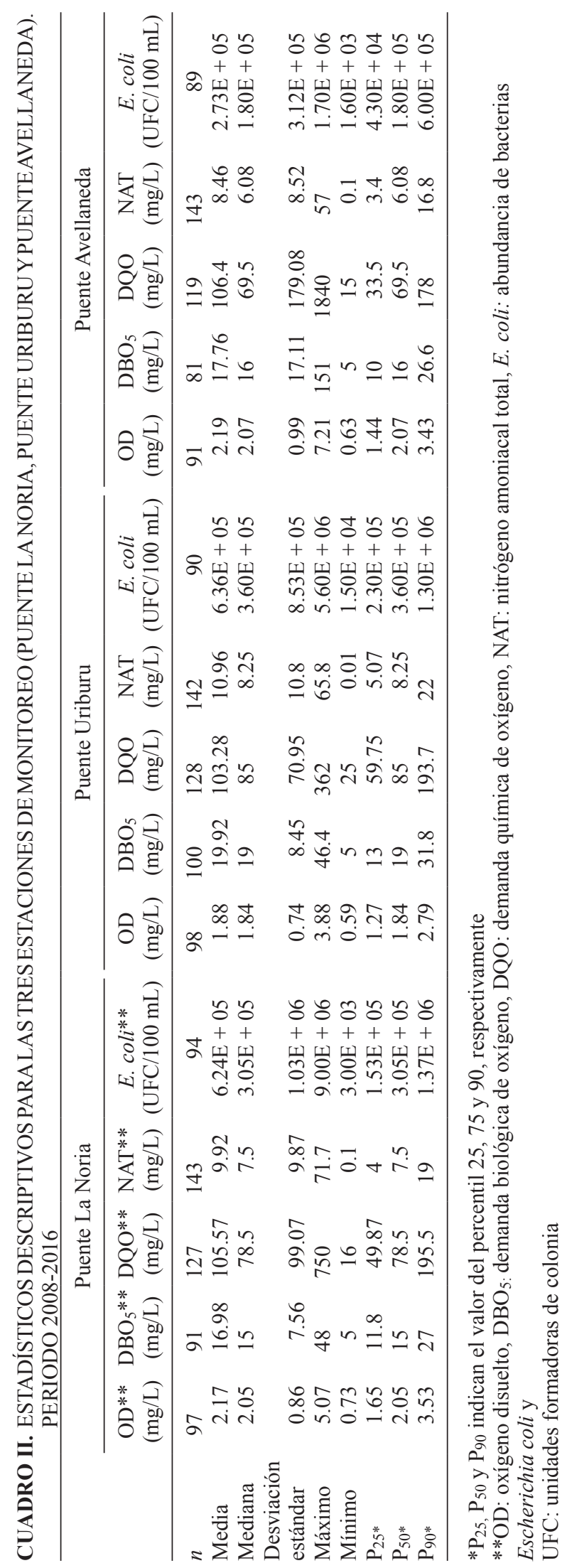



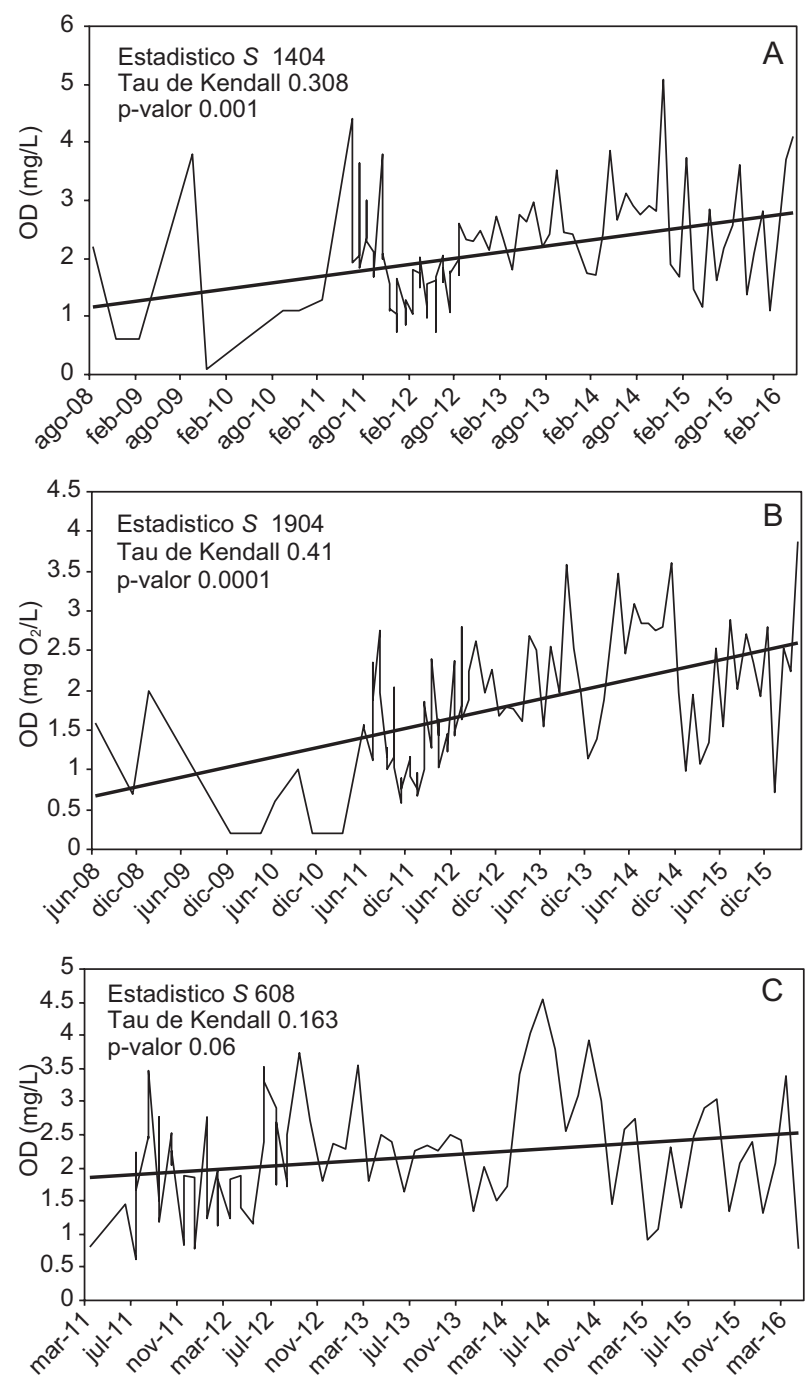

Fig. 2. Valor del estadístico $S$ de la prueba de Mann-Kendall y evolución de los valores de OD (oxígeno disuelto en $\mathrm{mg} / \mathrm{L}$ ) en Puente La Noria (a), Puente Uriburu (b) y Puente Avellaneda (c) en el periodo 2008-2016

\section{Demanda biológica de $\mathrm{O}_{5}\left(\mathrm{DBO}_{5}\right)$}

Como puede observarse en el cuadro II, el valor de la media resultó levemente superior al valor de la mediana en las tres estaciones de monitoreo, y este último fue superior a $15 \mathrm{mg} \mathrm{O}_{2} / \mathrm{L}$ (criterio de máximo admisible previsto en el uso IV “actividades recreativas pasivas" para $\mathrm{DBO}_{5}$ ), tanto en Puente Uriburu como en Puente Avellaneda. De acuerdo con el cálculo de los percentiles, el $50 \%$ de las mediciones en Puente la Noria y Puente Avellaneda presentaron valores inferiores a $15 \mathrm{mg} \mathrm{O}_{2} / \mathrm{L}$. En Puente Uriburu, el porcentaje de las mediciones con dicho valor fue inferior al $50 \%$.

La tendencia decreciente para este parámetro (Fig. 3) fue estadísticamente significativa de acuerdo
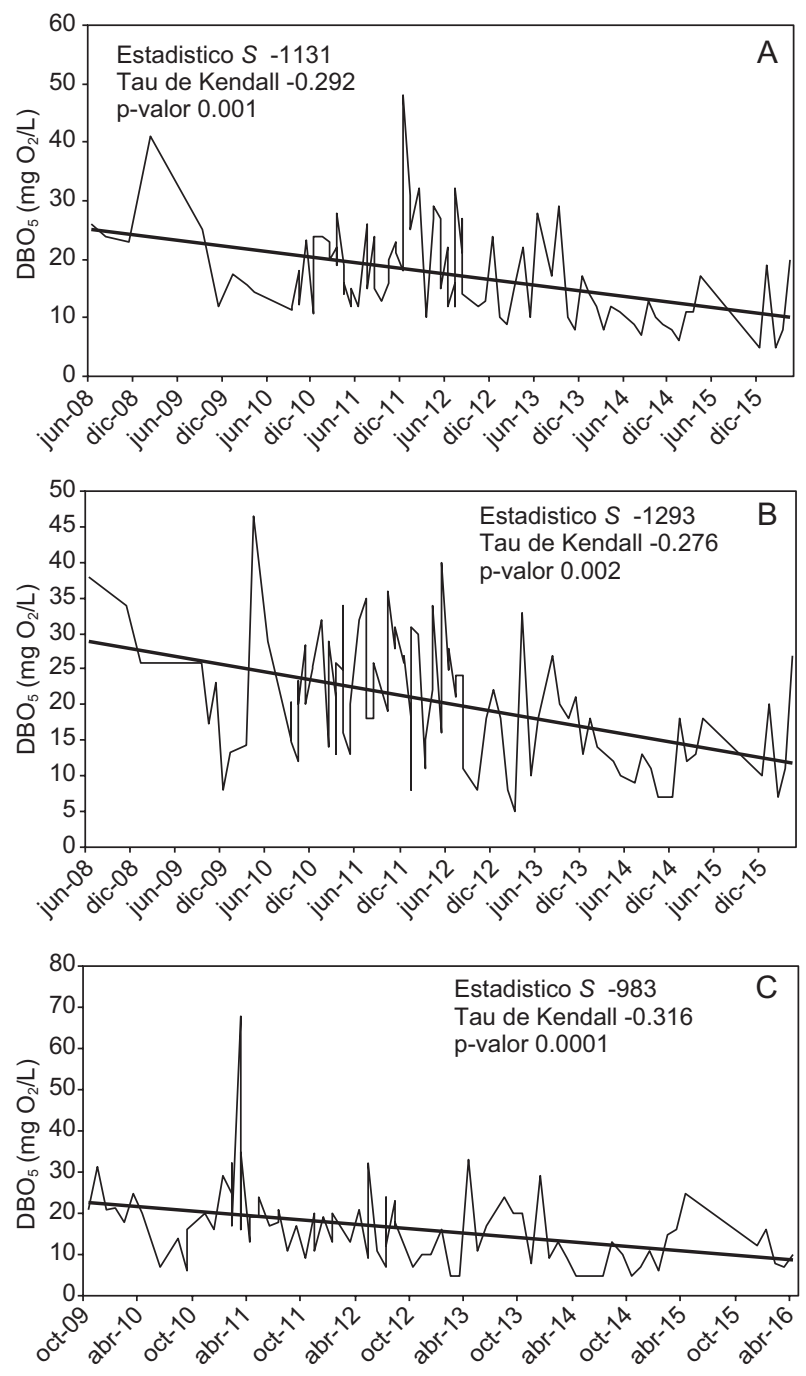

Fig. 3. Valor del estadístico $S$ de la prueba de Mann-Kendall y evolución de los valores de $\mathrm{DBO}_{5}$ (demanda biológica de oxígeno 5 en $\mathrm{mg} \mathrm{O}_{2} / \mathrm{L}$ ) en Puente La Noria (a), Puente Uriburu (b) y Puente Avellaneda (c) en el periodo 20082016.

con la prueba de Mann-Kendall $(\mathrm{p}<0.05)$ en las tres estaciones de monitoreo. En cuanto al cumplimiento del valor máximo establecido en el uso IV, puede observarse que en la serie de mediciones realizadas hasta fin de 2013 muy pocas presentaron valores $\leq 15 \mathrm{mg} \mathrm{O}_{2} / \mathrm{L}$; en años posteriores, más del $60 \%$ de las mediciones reflejaron el cumplimiento del uso IV en los tres puntos de muestreo.

\section{Demanda química de oxígeno (DQO)}

El valor de la media del DQO en el periodo 2008-2016 fue mayor que el valor de la mediana en las tres estaciones de monitoreo (cuadro II). Esta diferencia se debió a que se registraron valores 
muy elevados en todos los puntos, especialmente en Puente la Noria y Puente Avellaneda. ACUMAR estableció un límite de emisión para este parámetro de $250 \mathrm{mg} \mathrm{O}_{2} / \mathrm{L}$. Además, la Ley 26221 establece, para las plantas depuradoras de líquidos cloacales con tratamiento secundario, un límite de emisión de $125 \mathrm{mg} \mathrm{O}_{2} / \mathrm{L}$. El $25 \%$ de valores superó este límite en las tres estaciones de monitoreo. Por otra parte, en Puente Uriburu y Puente la Noria, el $25 \%$ de los datos fue inferior a $50 \mathrm{mg} \mathrm{O}_{2} / \mathrm{L}$. En Puente Avellaneda, el $25 \%$ de los datos presentó valores inferiores a $33.5 \mathrm{mg} \mathrm{O}_{2} / \mathrm{L}$.

La tendencia creciente para este parámetro en las tres estaciones de monitoreo (Fig. 4) fue estadísticamente significativa, aunque con una correlación de moderada a baja con el factor tiempo (valores tau de Kendall menores de 0.2 en Puente la Noria y Puente Uriburu).

\section{Nitrógeno amoniacal total (NAT)}

El valor de la mediana fue menor que la media en las tres estaciones de monitoreo (cuadro II). El uso IV no establece un criterio de calidad para el nitrógeno amoniacal total, por lo cual se seleccionó, con fines comparativos, la normativa de países limítrofes relativa a usos del agua similares al uso IV. La resolución 357 del Consejo Nacional de Medio Ambiente del Brasil (CONAMA 2005) establece para aguas superficiales con el uso de la clase III (que incluye la recreación con contacto secundario, es decir, contacto con agua esporádico o accidental) un valor máximo de $5.6 \mathrm{mg} / \mathrm{L}$. En las tres estaciones de monitoreo en el Riachuelo, entre el $50 \%$ y el $75 \%$ de las mediciones resultaron superiores a dicho límite.

La tendencia decreciente para este parámetro (Fig. 5) fue estadísticamente significativa de acuerdo con la prueba de Mann-Kendall $(\mathrm{p}<0.05)$ en las tres estaciones de monitoreo.

\footnotetext{
Abundancia de bacterias $E$. coli

De acuerdo con el cuadro II, la media y la mediana se mantuvieron en el mismo orden de magnitud, ambas levemente menores en Puente Avellaneda respecto a Puente Uriburu y Puente la Noria. La mayor variabilidad en los datos se observó en Puente la Noria, donde se registró el valor más elevado $(9 \mathrm{E}$ + $06 \mathrm{UFC} / 100 \mathrm{~mL}$ ). El valor más bajo registrado $(1.6 \mathrm{E}+03 \mathrm{UFC} / 100 \mathrm{~mL})$ (cuadro II) resultó superior al límite máximo establecido en la resolución 357 de CONAMA de $2.5 \mathrm{E}+02$ coliformes fecales o termotolerantes/ $100 \mathrm{~mL}$ para el uso de la clase III, el cual incluye recreación con contacto secundario
}
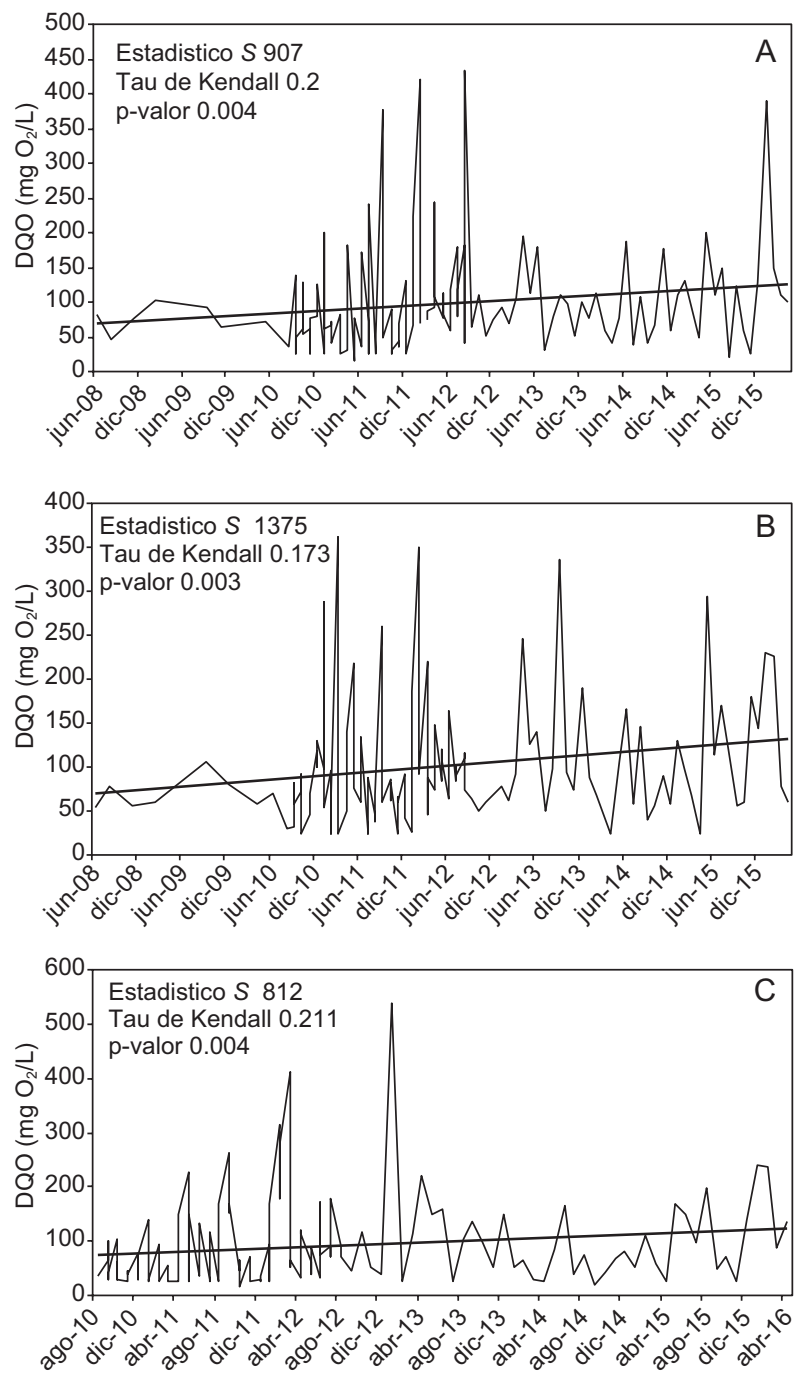

Fig. 4. Valor del estadístico $S$ de la prueba de Mann-Kendall y evolución de los valores de DQO (demanda química de oxígeno en $\mathrm{mg} \mathrm{O}_{2} / \mathrm{L}$ ) en Puente la Noria (a), Puente Uriburu (b) y Puente Avellaneda (c) en el periodo 20082016.

(utilizado a modo comparativo por la ausencia de inclusión de este parámetro microbiológico en el uso IV y la incompatibilidad de las unidades de expresión entre los valores del monitoreo y el límite de emisión establecido por ACUMAR).

En Puente la Noria se obtuvo una tendencia estadísticamente decreciente para abundancia de $E$. coli $(\mathrm{p}=0.04)$ y la correlación entre el parámetro y el factor tiempo presentó un valor tau de Kendall inferior a 0.2 (Fig. 6).

\section{Ion cloruro $\left(\mathrm{Cl}^{-}\right)$}

En Puente la Noria y Puente Uriburu, el valor de la media fue algo inferior al valor de la mediana; a su 

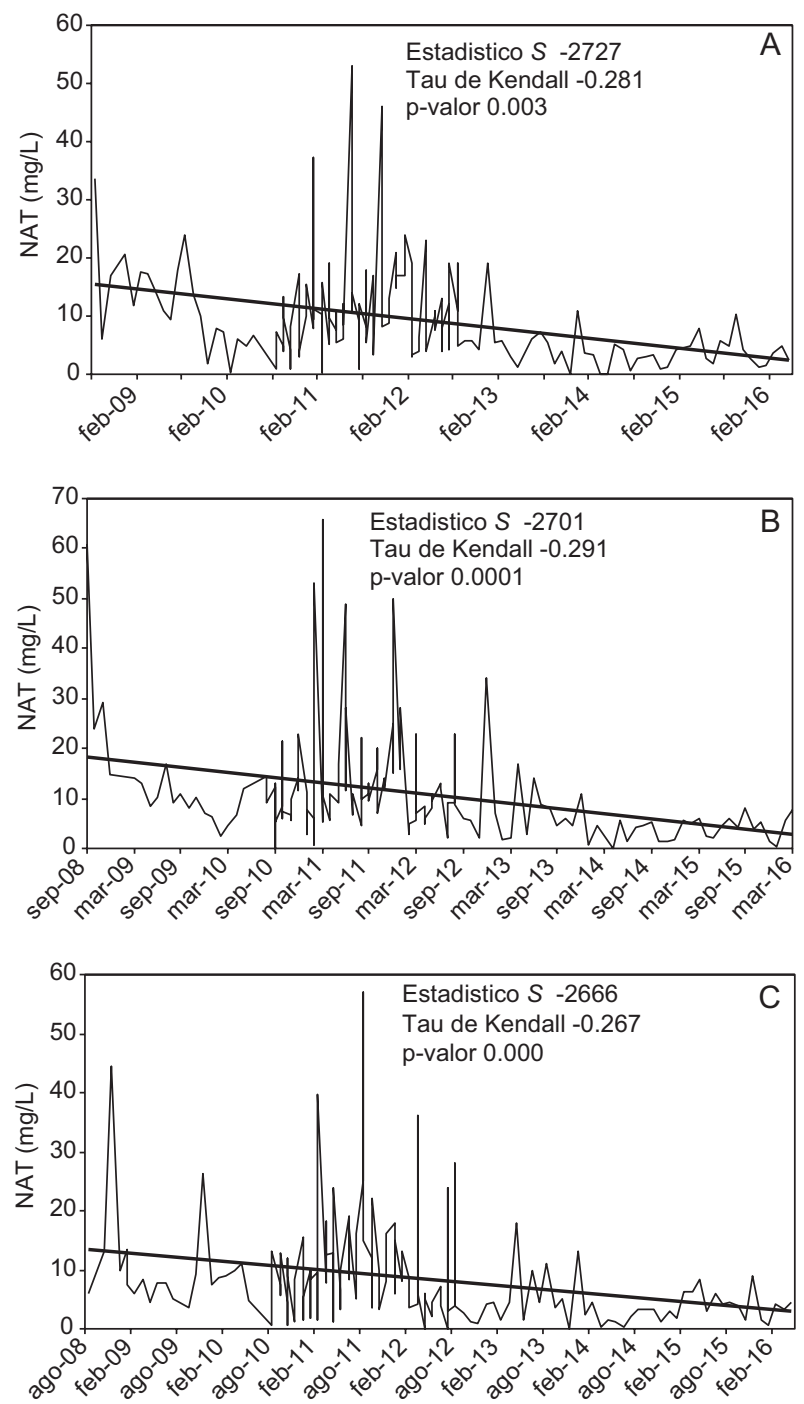

Fig. 5. Valor del estadístico $S$ de la prueba de Mann-Kendall y evolución de los valores de NAT (nitrógeno amoniacal total en $\mathrm{mg} / \mathrm{L}$ ) en Puente la Noria (a), Puente Uriburu (b) y Puente Avellaneda (c) en el periodo 2008-2016.

vez, estos valores duplicaron los correspondientes a Puente Avellaneda (cuadro III). El mayor rango de variación en los datos se observó en Puente la Noria debido a que en este sitio se registraron los valores más elevados y más bajos de la serie, 500 y $12 \mathrm{mg} / \mathrm{L}$, respectivamente. El cálculo de los percentiles indicó que el porcentaje de los datos con valores inferiores a $200 \mathrm{mg} / \mathrm{L}$ aumentó hacia la desembocadura. En Puente la Noria, entre el $25 \%$ y el $50 \%$ de los valores registrados resultaron menores de $250 \mathrm{mg} / \mathrm{L}$ (criterio de calidad para el cloruro en el uso de la clase III que incluye la recreación con contacto secundario, CONAMA 2005); en cambio, en Puente Avellaneda

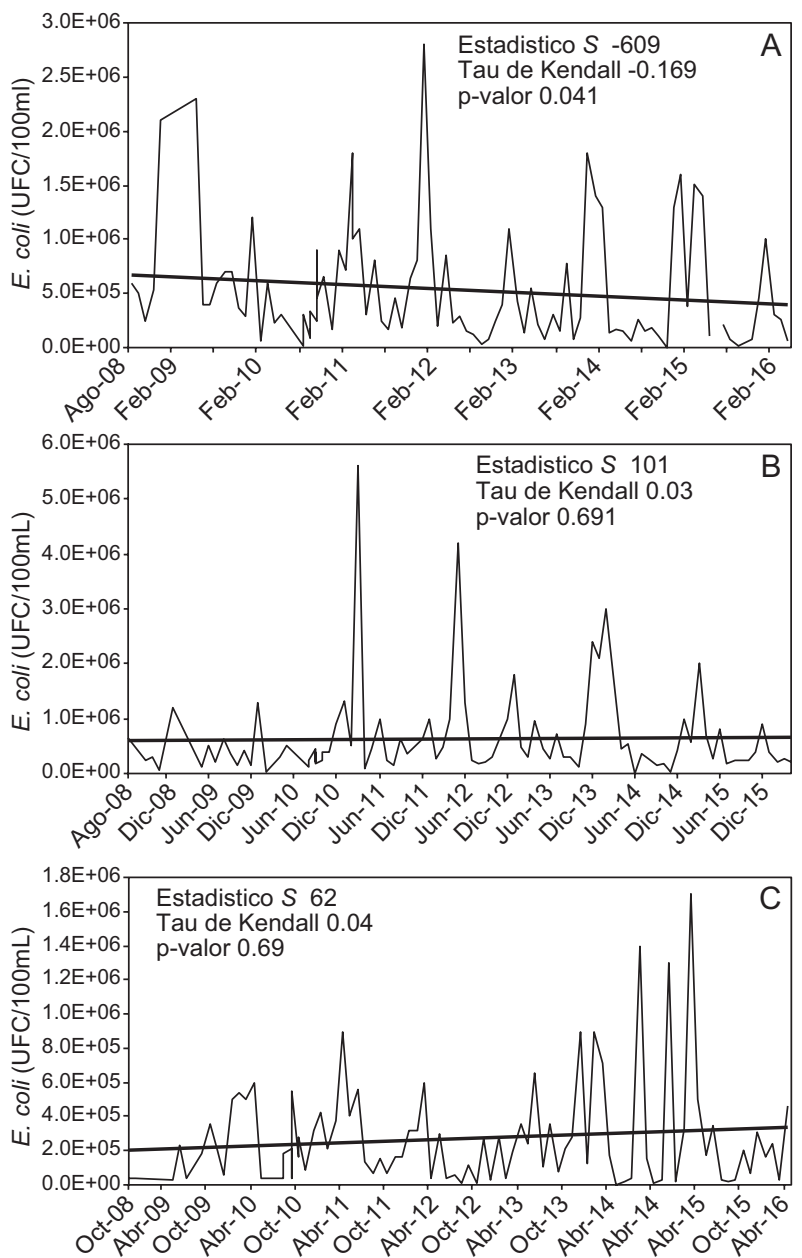

Fig. 6. Valor del estadístico $S$ de la prueba de Mann-Kendall y evolución de los valores de abundancia de Escherichia coli en unidades formadoras de colonia en $100 \mathrm{ml}$ (UFC/100ml) en Puente la Noria (a), Puente Uriburu (b) y Puente Avellaneda (c) en el periodo 2008-2016.

el $90 \%$ de los datos resultaron inferiores a dicho valor.

Los valores de ion cloruro mostraron una tendencia decreciente (Fig. 7) en el periodo 2008-2016. La prueba de Mann-Kendall indicó que dicha tendencia ha sido significativa $(\mathrm{p}<0.05)$ en los tres sitios.

\section{Precipitación mensual}

En el caso de este parámetro meteorológico, entre 2008 y 2016 la precipitación mensual fue muy variable para el área de la ciudad de Buenos Aires. El valor medio mensual fue de $106.9 \mathrm{~mm}$ con un pico de 421 $\mathrm{mm}$ y un mínimo de $7 \mathrm{~mm}$ (cuadro III). Alrededor del $50 \%$ de los datos mensuales registrados mostró valores superiores a $100 \mathrm{~mm}$. 
CUADRO III. ESTADÍSTICOS DESCRIPTIVOS PARA LAS TRES ESTACIONES DE MONITOREO (PUENTE LA NORIA, PUENTE URIBURU Y PUENTE AVELLANEDA). PERIODO 2008-2016

\begin{tabular}{|c|c|c|c|c|}
\hline & \multicolumn{3}{|c|}{ Ion cloruro $(\mathrm{mg} / \mathrm{L})$} & \multirow{2}{*}{$\begin{array}{c}\text { Precipitación media mensual } \\
\text { en la Ciudad Autónoma de } \\
\text { Buenos Aires (mm) }\end{array}$} \\
\hline & $\begin{array}{l}\text { Puente } \\
\text { la Noria }\end{array}$ & $\begin{array}{l}\text { Puente } \\
\text { Uriburu }\end{array}$ & $\begin{array}{c}\text { Puente } \\
\text { Avellaneda }\end{array}$ & \\
\hline$n$ & 143 & 141 & 142 & 96 \\
\hline Media & 236.3 & 215.82 & 141.61 & 106.9 \\
\hline Mediana & 247 & 225 & 129.5 & 91.4 \\
\hline $\begin{array}{l}\text { Desviación } \\
\text { estándar }\end{array}$ & 85.3 & 63.31 & 62.13 & 82.62 \\
\hline Máximo & 500 & 395 & 305 & 421 \\
\hline Mínimo & 12 & 21 & 23 & 7 \\
\hline $\mathrm{P}_{25 *}$ & 203.5 & 193 & 85 & 41.35 \\
\hline $\mathrm{P}_{50 *}$ & 247 & 225 & 129.5 & 91.35 \\
\hline $\mathrm{P}_{90 *}$ & 323.6 & 281 & 223 & 239.5 \\
\hline
\end{tabular}

${ }^{*} \mathrm{P}_{25}, \mathrm{P}_{50}$ y $\mathrm{P}_{90}$ indican el valor del percentil 25,75 y 90 , respectivamente

En la figura 8 puede observarse la evolución temporal de la precipitación mensual con una aparente tendencia creciente para el periodo de estudio. De acuerdo con la prueba de Mann-Kendall, dicha tendencia resultó estadísticamente significativa $(\mathrm{p}=0.008)$.
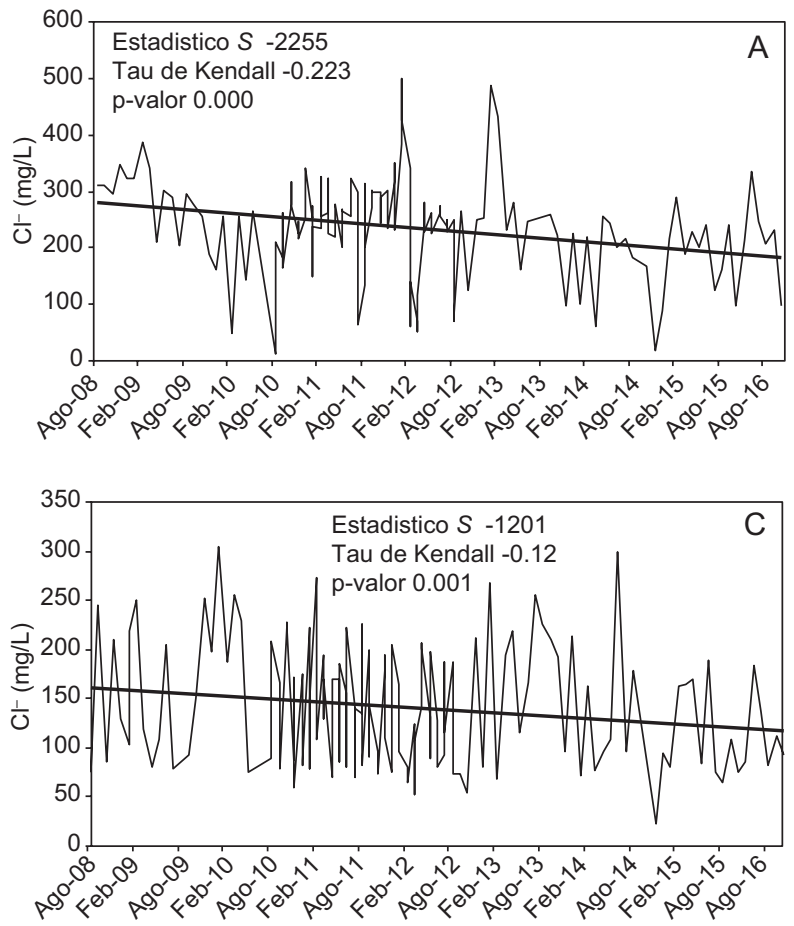

Fig. 7. Valor del estadístico $S$ de la prueba de Mann-Kendall y evolución de los valores de $\mathrm{Cl}^{-}$(ion cloruro en mg/L), en Puente La Noria (a), Puente Uriburu (b) y Puente Avellaneda (c) en el periodo 2008-2016.

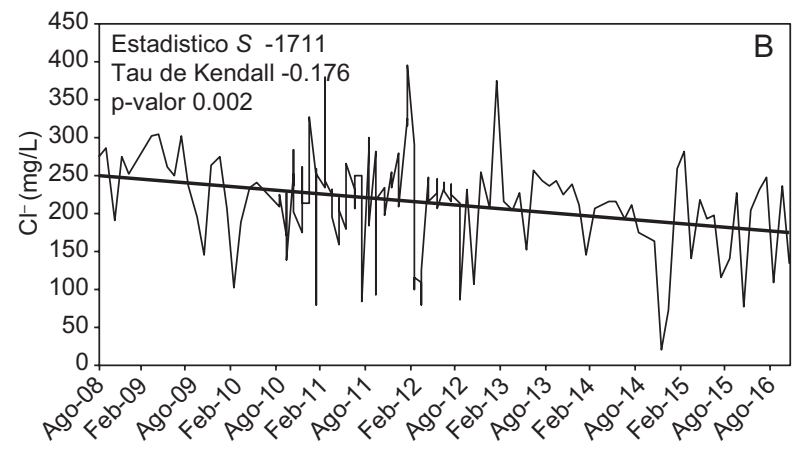

\section{DISCUSIÓN}

El análisis de tendencias aquí presentado indicó que en el periodo 2008-2016, las aguas del Riachuelo mostraron tendencias estadísticamente significativas decrecientes en los valores de $\mathrm{DBO}_{5}, \mathrm{NAT}_{\text {y } \mathrm{Cl}^{-}}$en 

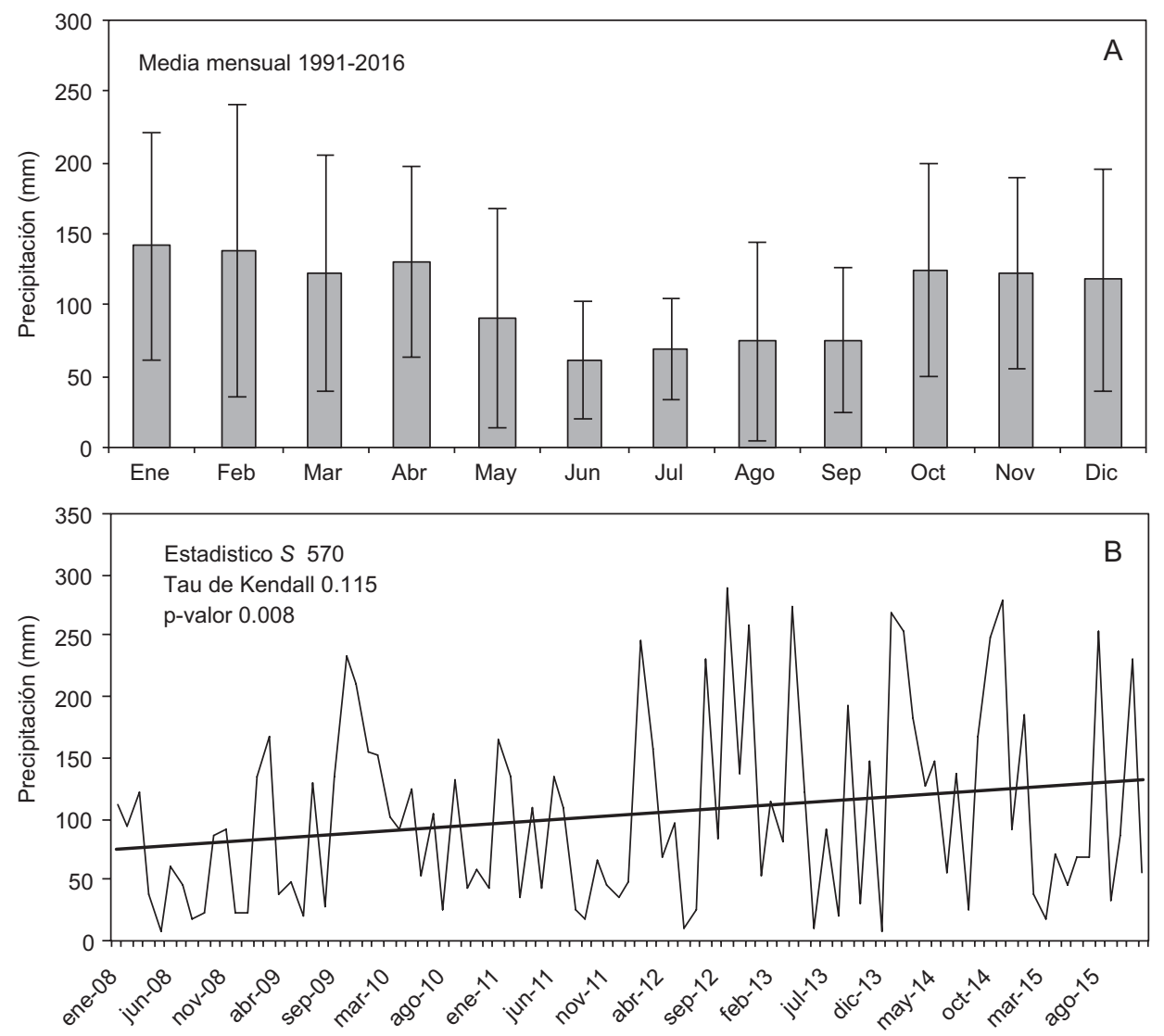

Fig. 8. Precipitación mensual ( $\mathrm{mm}$ ) para el área de la Ciudad Autónoma de Buenos Aires (a) y valor del estadístico $S$ de la prueba de Mann-Kendall (b) en el periodo 2008-2016.

los tres puntos de monitoreo, y reducción de E. coli únicamente en Puente la Noria. La significación estadística de esta última tendencia resultó menor respecto al resto de las variables $(\mathrm{p}=0.04)$; es decir, se trata de una tendencia menos acentuada. Las fuentes de $\mathrm{DBO}_{5}, \mathrm{NAT}, \mathrm{Cl}^{-}$y E. coli al Riachuelo están constituidas por el conjunto de descargas de plantas depuradoras de líquidos cloacales y descargas industriales directas al curso o indirectas vía conexión al colector pluvial. A estas fuentes deben adicionarse las descargas indirectas de líquidos cloacales al mismo colector, que recoge también la materia orgánica biodegradable depositada en las calles de la ciudad.

Por su parte, pese a la reducción de la $\mathrm{DBO}_{5}$, la DQO mostró un patrón de incremento en sus valores en todo el tramo del río. Este aumento implica una mayor descarga al río de compuestos orgánicos cuya biodegradación requiere más tiempo o de sustancias inorgánicas que pueden ser oxidadas (cloruros, nitritos, metales, sulfuros, amoníaco, fósforo soluble, sólidos suspendidos). Las fuentes de este tipo de compuestos para el Riachuelo son básicamente las mismas que para los parámetros antes nombrados, es decir, descargas industriales, líquidos cloacales y la escorrentía urbana.

ACUMAR ha identificado 16267 establecimientos industriales asociados a la cuenca, entre los cuales 931 han sido clasificados como agentes contaminantes. Entre las principales actividades industriales que constituyen agentes contaminantes se encuentran curtiembres, frigoríficos, carnes y derivados; las industrias químicas y petroquímicas, de alimentos y bebidas, y galvanoplastias. De acuerdo con el PISA, actualizado recientemente por ACUMAR, el organismo está focalizado en el control de algo más de 100 establecimientos que estadísticamente son críticos en lo concerniente a su aporte en carga orgánica. Asimismo, información generada por la Subsecretaría de Ambiente y Desarrollo Sustentable de Argentina señaló al curtido de cueros como la industria responsable del $50 \%$ de los contaminantes presentes en el curso de agua, seguida por los frigoríficos (SAyDS 2006). Los efluentes de este tipo de actividades industriales aportan al río, en proporciones diferentes, los 
parámetros aquí analizados (a excepción de E. coli). El efluente promedio de una industria del curtido de cueros cuenta con valores de DQO de $4000 \mathrm{mg}$ $\mathrm{O}_{2} / \mathrm{L}, 2000 \mathrm{mg} \mathrm{O}_{2} / \mathrm{L}_{\mathrm{de}} \mathrm{DBO}_{5}, 5000 \mathrm{mg} / \mathrm{L}$ de cloruro, $130 \mathrm{mg} / \mathrm{L}$ de aceites y grasas, $160 \mathrm{mg} / \mathrm{L}$ de sulfuros, $150 \mathrm{mg} / \mathrm{L}$ de cromo trivalente, $2000 \mathrm{mg} / \mathrm{L}$ de sólidos en suspensión y $1400 \mathrm{mg} / \mathrm{L}$ de sulfato (UNIDO 2011). Otras actividades industriales como la farmacéutica generan efluentes con valores muy superiores de DQO que llegan a $80000 \mathrm{mg} \mathrm{O} / \mathrm{L}$ (Nandy y Kaul 2001). Es decir, teniendo en consideración el número de establecimientos de este tipo y, sobre todo, el caudal de descarga de sus efluentes, si éstos no reciben un tratamiento adecuado, el impacto sobre el cuerpo de agua receptor puede ser muy importante. En los líquidos cloacales, por su parte, puede hallarse una gran variedad de compuestos orgánicos, algunos también presentes en los efluentes industriales, originados a partir del uso de productos de cuidado personal y productos de limpieza (Deblonde et al. 2011). Más aún, los ríos dominados por efluentes podrían considerarse como sitios de concentración especialmente elevada para este tipo de sustancias debido a que en ellos la dilución es prácticamente nula (Brooks et al. 2006). Este tipo de efluente está caracterizado, principalmente, por la presencia de elevados niveles de materia orgánica biodegradable, cloruros, compuestos biogénicos y medicamentos, así como el componente microbiano. Esto implica que los efluentes cloacales aportan a la DQO no sólo materia orgánica biodegradable, sino también una amplia gama de compuestos orgánicos sintéticos y fracción inorgánica oxidable.

En áreas urbanas, el agua de escorrentía pluvial por sí misma contiene compuestos de naturaleza diversa. El Riachuelo, en particular, recibe la escorrentía pluvial de la CABA a través de varios arroyos entubados (Escalada/Larrazábal, Cildañez, Erezcano, Ochoa y Elía) y las aguas de escorrentía de los barrios de La Boca y Barracas (Fig. 1). En la margen derecha recibe descargas pluviales provenientes del partido de Lanús. De acuerdo con estudios previos de caracterización de la escorrentía pluvial en eventos de tormenta, los valores de DQO presentes en este tipo de descargas es ampliamente variable.

Considerando estudios provenientes de países donde el colector pluvial no recibe descargas industriales ni cloacales directas, para áreas residenciales con alta densidad poblacional y actividad comercial, Lee y Bang (2000) informaron valores de DQO en un rango de 21 a $1455 \mathrm{mg} \mathrm{O}_{2} / \mathrm{L}$. Chow et al. (2011), por su parte, reportaron para un área comercial un valor medio de DQO por evento de precipitación de
$192 \mathrm{mg} \mathrm{O} / \mathrm{L}$. Para un área residencial y comercial, Li et al. (2015) informaron valores medios por evento de $302 \pm 151 \mathrm{mg} \mathrm{O}_{2} / \mathrm{L}$, con un máximo de 567 y de $221 \pm 126 \mathrm{mg} \mathrm{O}_{2} / \mathrm{L}$ para un área industrial, con un pico de $486 \mathrm{mg} \mathrm{O}_{2} / \mathrm{L}$.

ACUMAR incluye en su monitoreo el análisis de los pluviales en el punto de descarga. El análisis de los valores publicados para uno de ellos, identificado como Conducto Erezcano, indicó un valor de la mediana para la DQO de $157 \mathrm{mg} \mathrm{O}_{2} / \mathrm{L}$ con un máximo de 1331 y un mínimo de 29, para el periodo de muestreo. Para la $\mathrm{DBO}_{5}$, el valor de la mediana para el mismo periodo fue de $69.8 \mathrm{mg} \mathrm{O}_{2} / \mathrm{L}$ con un máximo de $588 \mathrm{mg} \mathrm{O}_{2} / \mathrm{L}$. Debe considerarse que los valores citados provenientes de la bibliografía constituyen valores medios por evento de precipitación, momentos en los cuales el flujo se ve incrementado y, por lo tanto, también el aporte de dichos compuestos. Los compuestos orgánicos que conforman la DQO en la escorrentía pluvial provienen de diversas fuentes puntuales (estaciones expendedoras de combustible con descargas directas o pérdidas en los contenedores de almacenamiento, conexiones del colector cloacal y de diversas actividades industriales) y fuentes difusas (combustión, pavimento, pérdida de aceites y grasas del parque automotor, deposición atmosférica seca y húmeda, desgaste de neumáticos) (Harper 1998). Entre las sustancias orgánicas se han detectado hidrocarburos aromáticos policíclicos (HAP), bifenilos policlorados (BPC), aceites y grasas, y compuestos orgánicos volátiles, así como otras sustancias que aún no se han identificado, pero se encuentran representadas en el carbono orgánico total y en la DQO (a excepción de los aromáticos).

Cabe destacar que el número de vehículos que ingresan por día a la CABA se ha incrementado de 650000 en 1998 a 1300000 en 2012. De acuerdo con el estudio realizado por la Dirección General de Estadísticas y Censos GCBA, el parque automotor activo en la ciudad es de casi 1450000 vehículos (Buenos Aires Ciudad 2016b) Sería importante determinar si este incremento en el parque automotor ha influenciado cuantitativa y cualitativamente en el aporte de sustancias orgánicas que conforman la DQO por escorrentía pluvial.

En cuanto a las fuentes de microorganismos indicadores de contaminación por efluentes cloacales, el río Matanza-Riachuelo recibe efluentes cloacales crudos a través del sistema colector pluvial y efluentes tratados (tratamiento secundario sin desinfección). Estos últimos provienen de las plantas depuradoras Sudoeste I y II, Santa Catalina y el Jagüel II, que descargan en el Matanza y tratan los efluentes de 
algo más de un millón de habitantes. En la cuenca alta del río se encuentran también plantas depuradoras (Cañuelas y Marcos Paz) que prestan el servicio para poblaciones más pequeñas, pero descargan sus efluentes en los afluentes del Matanza. Si bien no han sido objeto de análisis en este estudio, el monitoreo que realiza ACUMAR de la descarga de algunos pluviales de la ciudad de Buenos Aires y el partido de Lanús indica que los números de E. coli se encuentran en el rango de $1 \mathrm{E}+05$ y $1 \mathrm{E}+$ $07 \mathrm{UFC} / 100 \mathrm{~mL}$. Además, en otro colector pluvial como el arroyo Cildañez, los valores de $E$. coli para el periodo de estudio fueron de $2 \mathrm{E}+04$ y $4.5 \mathrm{E}+06$ UFC/100mL (ACUMAR 2016a). Considerando los valores de caudal, este arroyo constituiría un aporte importante de microorganismos. La consecuencia de estas descargas a un curso de agua como el Riachuelo con mínima dilución se encuentra expresada en los valores medios de $E$. coli obtenidos para las tres estaciones de monitoreo. En el periodo de estudio, los valores de E. coli en el Riachuelo resultaron similares a los reportados en la bibliografía para efluentes cloacales crudos (valor medio de coliformes fecales de 2.1E + $05 \mathrm{UFC} / 100 \mathrm{~mL}$ ) (Anastasi et al. 2012).

En cuanto a la tendencia de los valores de oxígeno disuelto, los resultados indicaron que, para el caso particular de Puente Avellaneda, la tendencia de incremento observada no resultó estadísticamente significativa. En este caso, debe considerarse la influencia de las aguas del río de la Plata. Por otra parte, entre las acciones que se han llevado a cabo para contribuir a la recuperación de la calidad de las aguas del Riachuelo se encuentran la eliminación continua de los residuos flotantes en el espejo de agua y márgenes, y la extracción de más de 50 embarcaciones hundidas. Ambas acciones podrían haber favorecido el escurrimiento natural de las aguas $\mathrm{y}$, por lo tanto, una mayor oxigenación.

En cuerpos de agua con un régimen hidrológico natural, en general, la concentración de cloruros y de sólidos suspendidos varía con el caudal. En ríos dominados por efluentes, como es el caso de varios ríos urbanos con caudales base bajos como el Matanza-Riachuelo, la hidrología natural del curso se encuentra muy modificada. El caudal base puede incrementarse por las descargas continuas y la escorrentía pluvial (Onnis-Hayden et al. 2006). Los datos de caudal del río Matanza-Riachuelo no superan los 20 valores por estación de monitoreo. A pesar de esta limitación, se investigó estadísticamente su correlación con los valores de los sólidos suspendidos totales (no incluidos en el análisis de tendencias por ausencia de registros suficientes) y el ion cloruro para el mismo mes de medición en Puente la Noria. Esta estación de monitoreo fue seleccionada por encontrarse menos afectada por el régimen de marea del río de la Plata. El análisis mostró la ausencia de correlación de ambas variables con el caudal (información no mostrada), por lo tanto, este resultado refleja que el curso se encuentra influenciado por las descargas que recibe.

Cabe destacar que la información referida a caudal base y el uso asignado al curso es de suma importancia para calcular la carga máxima total diaria de un contaminante que puede recibir el curso manteniendo el uso asignado (USEPA 2016a). En este tipo de ríos - y el Matanza-Riachuelo no es la excepción-, utilizados históricamente como receptores y transportadores de efluentes, no suelen encontrarse disponibles datos de caudal base, lo cual dificulta la modelación de las emisiones.

El análisis de la precipitación acumulada mensual para la CABA indicó que esta variable se distribuyó homogéneamente a lo largo del año. Además, el análisis de tendencias para el periodo 2008-2016 indicó que el volumen acumulado mensual de precipitación en la ciudad se incrementó y 2014 constituyó el periodo con mayor precipitación total acumulada. A este respecto, entre las variables analizadas, OD y $\mathrm{DBO}_{5}$ mostraron un patrón distintivo en dicho año. Los valores medios de OD fueron levemente más elevados y los de $\mathrm{DBO}_{5}$ fueron menores en relación con otros años analizados. Asimismo, los valores de caudal registrados en la base de datos de ACUMAR muestran valores muy fluctuantes, pero más elevados durante 2014 en Puente la Noria y estaciones de monitoreo río arriba (información no mostrada). Este fenómeno no resulta tan evidente en estaciones de monitoreo río abajo donde la masa de agua y la sección promedio del curso se encuentran incrementadas por las descargas y la influencia de las aguas del río de La Plata. En cursos de agua dominados por efluentes, es esperable una reducción en la variabilidad temporal y espacial de la calidad y la cantidad de agua (Brooks et al. 2006). Aun así, y dado que los niveles de oxígeno tienden a incrementarse en la mayoría de las aguas superficiales durante periodos de mayor precipitación (USEPA 2016b), el incremento en la escorrentía pluvial y el escurrimiento posiblemente han influenciado no sólo los valores de $\mathrm{OD}$ y $\mathrm{DBO}_{5}$ durante 2014, sino también los valores del resto de los parámetros analizados en el periodo de estudio.

Los resultados obtenidos en el presente estudio indican que las intervenciones realizadas hasta hoy no habrían sido suficientes para controlar el ingreso de 
contaminantes orgánicos e inorgánicos al cuerpo de agua. La tendencia de incremento en los valores de DQO en los tres puntos de monitoreo implica un posible aumento en la toxicidad de las aguas del curso para las especies de la biota acuática.

En un curso con las características del MatanzaRiachuelo, el paradigma del efecto dilutorio del caudal no es suficiente. Los procesos de autodepuración de los ríos que contemplan la interacción del cauce con las riberas y con el propio lecho, están, en muchos ríos - como en este caso- limitados o son inexistentes debido a las intervenciones antrópicas en las riberas (erosión de las márgenes, perdida de la vegetación ribereña, construcciones, ingreso directo de contaminantes) y a la pésima calidad de los sedimentos que impide la acción de microorganismos bentónicos capaces de degradar la materia orgánica.

Siendo ambiciosos, avanzar a un uso de protección de la biota acuática implicaría necesariamente un incremento en el contenido de oxígeno, lo cual llevaría un tiempo considerable aun en un escenario de descarga cero. En las condiciones actuales, si bien se ha detectado un incremento en el oxígeno, que no estaría vinculado a una reducción en las descargas orgánicas, la tendencia de aumento en los valores de materia orgánica no biodegradable atenta contra la posibilidad de recuperación de la biota. En este aspecto, sería importante realizar una caracterización química de la DQO, para determinar los principales contribuyentes a este parámetro.

En un sistema tan complejo, el cumplimiento del uso IV y la ambición de alcanzar objetivos ambientales sostenibles para la cuenca sólo podría lograrse con una fuerte decisión política a nivel nacional, provincial y municipal de frenar el vertido de contaminantes y rehabilitar las riberas y sus sedimentos para propiciar la recuperación integral del ecosistema.

\section{CONCLUSIONES}

Los resultados del presente análisis de tendencias de la calidad de agua del Riachuelo reflejaron una evolución a condiciones más favorables en cuanto a concentraciones y demanda biológica de oxígeno, nitrógeno amoniacal y ion cloruro de 2008 a 2016. La fracción de materia orgánica no biodegradable se habría incrementado en todo el tramo al igual que la precipitación mensual para el área. En particular, es posible que el incremento de la escorrentía pluvial haya influenciado las tendencias en el periodo estu- diado. Aun así, el ecosistema permanece en un estado altamente degradado con un $50 \%$ de los valores registrados de oxígeno disuelto, demandas biológicas y químicas de oxígeno por debajo de los $2 \mathrm{mg} / \mathrm{L}$ y superiores a 15 y $50 \mathrm{mg} \mathrm{O}_{2} / \mathrm{L}$, respectivamente. La abundancia de E. coli, por su parte, no mostró ninguna tendencia apreciable y sus valores permanecen similares a los de un efluente cloacal crudo.

Es fundamental contar con una serie de datos más larga, homogénea en el tiempo y con mediciones de caudal que coincidan con el monitoreo de las variables de calidad, para validar las tendencias halladas o describir tendencias que no se han observado a partir de los datos disponibles.

\section{AGRADECIMIENTOS}

Los autores desean agradecer a la Gerencia Riachuelo y Borde Costero de la Agencia de Protección Ambiental-Gobierno de la Ciudad Autónoma de Buenos Aires, en especial a los licenciados Gabriel Giaccobone y Victoria Bottazzi, por ceder los datos de monitoreo de calidad de agua del Riachuelo; a la ingeniera Carolina Risolo, quien durante su cargo en la misma gerencia promovió el desarrollo del presente estudio, y a la doctora Amalia González por la confección del mapa de la cuenca.

\section{REFERENCIAS}

ACUMAR (2009). Anexo II usos. Criterios utilizados para la definición de los valores asociados a cada zona de uso. Autoridad de Cuenca Matanza Riachuelo [en línea]. http://www.acumar.gov.ar/ACUsentencias/CausaMendoza/2009abril/060409e/AnexoIIusos060409.pdf 26/10/16.

ACUMAR (2016a). Caracterización planialtimétrica y de las condiciones fisicoquímicas de los sedimentos y suelos del fondo del cauce del tramo rectificado Matanza-Riachuelo. Informe Final. Etapa 4. Autoridad de Cuenca Matanza-Riachuelo [en línea]. http:// www.acumar.gov.ar/content/documents/0/6230.pdf $14 / 4 / 17$

ACUMAR (2016b). Estaciones de medición de cursos de agua superficiales. Autoridad de Cuenca MatanzaRiachuelo. http://www.bdh.acumar.gov.ar:8081/bdh3/ aguasuperficial_listado.php 1/11/16

AGN (2006). Informe de Auditoria. Auditoria General de la Nación, Buenos Aires, Argentina [en línea]. http:/www.agn.gov.ar/informes/informesPDF2006/2006_024.pdf 6/09/16 
Anastasi E.M., Matthews B., Stratton H.M. y Katouli M. (2012). Pathogenic Escherichia coli found in sewage treatment plants and environmental waters. Appl. Environ. Microb. 78 (16), 5536-5541.

DOI: 10.1128/AEM.00657-12

APHA/AWWA/WPCF (1992). Métodos normalizados para el análisis de aguas potables y residuales. $17^{\mathrm{a}} \mathrm{ed}$. American Public Health Association, American Water Works Association, Water Environment Federation. Ed. Díaz de Santos, Madrid, España. 1325 pp.

Buenos Aires Ciudad (2016a). Precipitaciones (mm) mensuales. Ciudad de Buenos Aires. Enero 1991-diciembre 2016. Gobierno de la Ciudad de Buenos Aires [en línea]. https://www.estadisticaciudad.gob.ar/ eyc/?p=27703 3/10/16

Buenos Aires Ciudad (2016b). Mercado de vehículos automotores de la Ciudad de Buenos Aires. 1er. trimestre de 2016. Gobierno de la Ciudad de Buenos Aires [en línea]. http://www.estadisticaciudad.gob.ar/eyc/wpcontent/uploads/2016/08/ir_2016_1033.pdf 5/11/2016

Brigden K., Labunska I., Stringer R., Johnston P., Santillo D. y Ashton J. (2000). Contaminantes orgánicos y metales pesados en vertidos y sedimentos del Riachuelo, Argentina, 2000. Greenpeace [en línea]. http://www.greenpeace.org/argentina/Global/argentina/report/2009/5/ contaminantes-organicos-y-meta-2.pdf 2/8/16

Brooks B.W., Riley T.M. y Taylor R.D. (2006). Water quality of effluent-dominated ecosystems: Ecotoxicological, hydrological, and management considerations. En: Water quality: From assessment and ecotoxicology to remediation (S. Ostroumov, Ed.). Hydrobiologia 556 (1), 365-379. DOI: 10.1007/s10750-004-0189-7

Chow M.F., Yusop Z. y Mohamed M. (2011). Quality and first flush analysis of stormwater runoff from a tropical commercial catchment. Wa. Sci. Technol. 63 (6), 1211-1216. DOI: 10.2166/wst.2011.360

CONAMA (2005). Resolução No. 357. Conselho Nacional do Medio Ambiente [en línea]. http://www.mma.gov. $\mathrm{br} /$ port/conama/legiabre.cfm?codlegi=459 3/5/16.

Crichton N. (2001). Information point: Kendall's tau. J. Clin. Nurs. 10, 707-715 [en línea]. http://www. blackwellpublishing.com/specialarticles/jen_10_715. pdf 17/11/17.

Drapela K. y Drapelova I. (2011). Application of MannKendall test and the Sen's slope estimates for trend detection in deposition data from Bily Křiž (Beskydy Mts., the Czech Republic) 1997-2010. Beskydy 4 (2), 133-146 [en línea]. https://is.mendelu.cz/dok_server/ slozka.pl?download $=88743 ; \mathrm{id}=57763 ; \mathrm{z}=1$ 20/11/17

Deblonde T., Cossu-Leguille C. y Hartemann P. (2011). Emerging pollutants in wastewater: A review of the literature. Int. J. Hyg. Envir. Heal. 214 (6), 442-448. DOI: 10.1016/J.IJHEH.2011.08.002
Falczuk B. (2010). Aguas superficiales, cuenca del Matanza-Riachuelo [en línea]. http://archive.is/ nsrmT 20/4/17.

Fundación Ciudad (2002). Foro desarrollo sostenible de la cuenca Matanza-Riachuelo. Guía de Trabajo. Fundación Ciudad [en línea]. http://www.fundacionciudad. org.ar/pdf/Foro\%20MR-GTyD.pdf 4/10/16.

Greenpeace (2012). Cueros Tóxicos. Nuevas evidencias de contaminación de curtiembres en la cuenca MatanzaRiachuelo. Greenpeace Argentina, 26 pp. [en línea]. http://www.greenpeace.org/argentina/es/informes/ Cueros-toxicos/ 10/11/16

Hamed K.H. y Rao A.R. (1998). A modified Mann-Kendall trend test for autocorrelated data. J. Hydrol. 204 (1), 182-196. DOI: 10.1016/S0022-1694(97)00125-X

Harper H.H. (1998). Stormwater chemistry and water quality [en línea]. http://citeseerx.ist.psu.edu/viewdoc/ download?doi $=10.1 .1 .400 .4896 \&$ rep $=$ rep $1 \&$ type $=p$ df $1 / 11 / 16$.

Kendall M.G. (1975). Rank correlation methods. 4a ed. Charles Griffin, Londres, Reino Unido, 272 pp.

Lee J.H. y Bang K.W. (2000). Characterization of urban stormwater runoff. Water Res. 34 (6), 1773-1780. DOI: 10.1016/S0043-1354(99)00325-5

Li D., Wan J., Ma Y., Wang Y., Huang M. y Chen Y. (2015) Stormwater runoff pollutant loading distributions and their correlation with rainfall and catchment characteristics in a rapidly industrialized city. PLOS ONE 10 (3), e0118776.

DOI: $10.1371 /$ journal.pone. 0118776

Malpartida A. (2003). La cuenca del río Matanza-Riachuelo. Revisión de antecedentes de: recursos naturales y compuestos xenobióticos y otros polutantes en la cuenca. [en línea]. http://www.ambiente ecologico. com/ediciones/informesEspeciales/009_InformesEspeciales_MatanzaRiachuelo_AlejandroMalpartida. pdf $15 / 10 / 16$.

MJyDH (1993). Decreto 831/93. Reglamentación de la Ley $\mathrm{N}^{\circ}$ 24051. Ministerio de Justicia y Derechos Humanos, Buenos Aires, Argentina [en línea]. http:// www.minagri.gob.ar/sitio/areas/d_gestion_ambiental/ legislacion/nacional/_archivos//024051-LEY\%20 24051\%20(Residuos\%20peligrosos)/000999-DECRETO\%20831-93\%20(Reglamentación\%20de $\% 201 \mathrm{l} \% 20$ ley\%2024.051).pdf

Mann H.B. (1945). Nonparametric tests against trend. Econometrica 13 (3), 245-59.

DOI: $10.2307 / 1907187$

Nandy T. y Kaul S.N. (2001). Anaerobic pre-treatment of herbal-based pharmaceutical wastewater using fixedfilm reactor with recourse to energy recovery. Water Res. 35 (2), 351-362. DOI: 10.1016/S0043-1354(00)00263-3 
Onnis-Hayden A., Meharg R. y Peary R. (2006). Effluent dominated rivers. Center for Urban Environmental Studies, Northeastern University [en línea]. http://hdl. handle.net/2047/d20003534 2/11/16.

Onoz B. y Bayazit M. (2003). The power of statistical tests for trend detection. Turk. J. Eng. Environ. Sci. 27 (4), 247-251.

Tabari H., Marofi S., Aeini A., Talaee P.H. y Mohammadi K. (2011). Trend analysis of reference evapotranspiration in the western half of Iran. Agr. Forest Meteorol. 151 (2), 128-136. DOI: 10.1016/j.agrformet.2010.09.009

UNIDO (2011). Introduction to treatment of tannery effluents. What every tanner should know about effluent treatment. United Nations Industrial Development Organization, Vienna, $69 \mathrm{pp}$.

USEPA (2016a). Clean Water Act Section 303(d): Impaired waters and total maximum daily loads (TMDLs) [en línea]. https://www.epa.gov/tmdl 20/11/16
USEPA (2016b). Causal Analysis/Diagnosis Decision Information System (CADDIS): Volume 2: Sources, stressors \& responses. Dissolved oxygen. Office of Research and Development, Washington, DC [en línea]. https://www.epa.gov/caddis-vol2/caddis-volume-2-sources-stressors-responses-dissolved-oxygen $22 / 11 / 2016$

Varol M. y Sen B. (2009). Assessment of surface water quality using multivariate statistical techniques: a case study of Behrimaz Stream, Turkey. Environ. Monit. Assess. 159 (1-4), 543-553.

DOI: $10.1007 / \mathrm{s} 10661-008-0650-6$

Walsh C.J., Roy A.H., Feminella J.W., Cottingham P.D., Groffman P.M. y Morgan R.P. II (2005). The urban stream syndrome: Current knowledge and the search for a cure. J. N. Am. Benthol. Soc. 24 (3), 706-723. DOI: 10.1899/04-028.1 